International Electronic Scientific Journal "Science Online” http://nauka-online.com/

Биологические науки

УДК 336.72

Федосеева Дарья Михайловна

кандидат биологических наук, младший научный сотрудник Институт молекулярной биологии имени В.А. Энгельгардта РАН Чуриков Николай Андреевич доктор биологических наук, профессор, Институт молекулярной биологии имени В.А. Энгельгардта РАН

\title{
ВЛИЯНИЕ ЭНХАНСЕРА СОРІА И ИНСУЛЯТОРА GYPSY НА СИНТЕЗ ЭРНК, МОДИФИКАЦИИ ХРОМАТИНА И СВЯЗЫВАНИЕ ИНСУЛЯТОРНЫХ БЕЛКОВ ВТРАНСФЕЦИРОВАННЫХ ГЕНЕТИЧЕСКИХ КОНСТРУКЦИЯХ
}

Аннотация. Энхансеры и инсуляторы являются одними из ключевых регуляторов экспрессии генов в геноме. Тем не менее, не смотря на многочисленные исследования, механизмы обеспечивающие работу этих регуляторных элементов до конц̧а не изучены. Mы проанализировали отдельные эфеекты, которые оказывает энхансер и инсулятор из мобильных элементов соріа и gурsу соответственно с использованием трансфециированных генетических конструкиий. Созданная нами система конструкиий исключает влияние геномного окружения. Мы обнаружили синтез эРНК, длинной от 350-1050 п.н. а также наличие специфрических меток хроматина $3 \mathrm{~K} 4$ mе3 H3K418aс в регионе, удаленном от энхансера на 300 п.н. Введение в конструкцию инсулятора между энхансером и промотором подавляет эти эффектыл. Также мы обнаружили связывание dCTCF с энхансером и инсулятором gурsу. Mы предполагаем, что один инсулятор может взаимодействовать с энхансером, тогда как два инсулятора преимущуественно взаимодействуют друг с другом. Наши данные подтверждают гипотезу о сущуествовании петель хроматина, формируемых данными регуляторными элементами.

International Electronic Scientific Journal "Science Online” http://nauka-online.com/ 
Ключевые слова: Регуляция экспрессии генов, энхансеры, инсуляторы, энхансерные РНК, модификаџии хроматина.

Первостепенная задача современной науки - изучение механизмов регуляции экспрессии генов. На данный момент эта область науки активно изучается, однако многие аспекты данной области до конца не изучены. Одним из важных вопросов в процессах генной регуляции являются механизмы работы регуляторных элементов генома.

Что нам известно? С уверенностью можно сказать лишь то, что в большинстве своем механизмы функционирования энхансеров и инсуляторов построены на эпигенетических процессах. Этот вывод был сделан на основе исследований механизмов работы регуляторных элементов генома. Для решения этой задачи мы создали генетические конструкции, включающие в себя энхансер соріа мобильного элемента соріа; и конструкции, содержащие 1-2 инсулятора gypsy (в позиции «до» и «после» репортерного гена). Функционал регуляторных элементов был экспериментально проверен с помощью ко-трансфекции.

На первом этапе работы проведено исследование стартов транскрипции эРНК (TSS эРНК) с использованием метода 5'RACE. После него мы проанализировали PCR-продукты путем мультиплексного однонаправленного глубокого секвенирования на платформе 454. В итоге получено 2895 чтений. Максимум TSS находился в области, удаленной от энхансера на 265 п.н. (рис.1). 


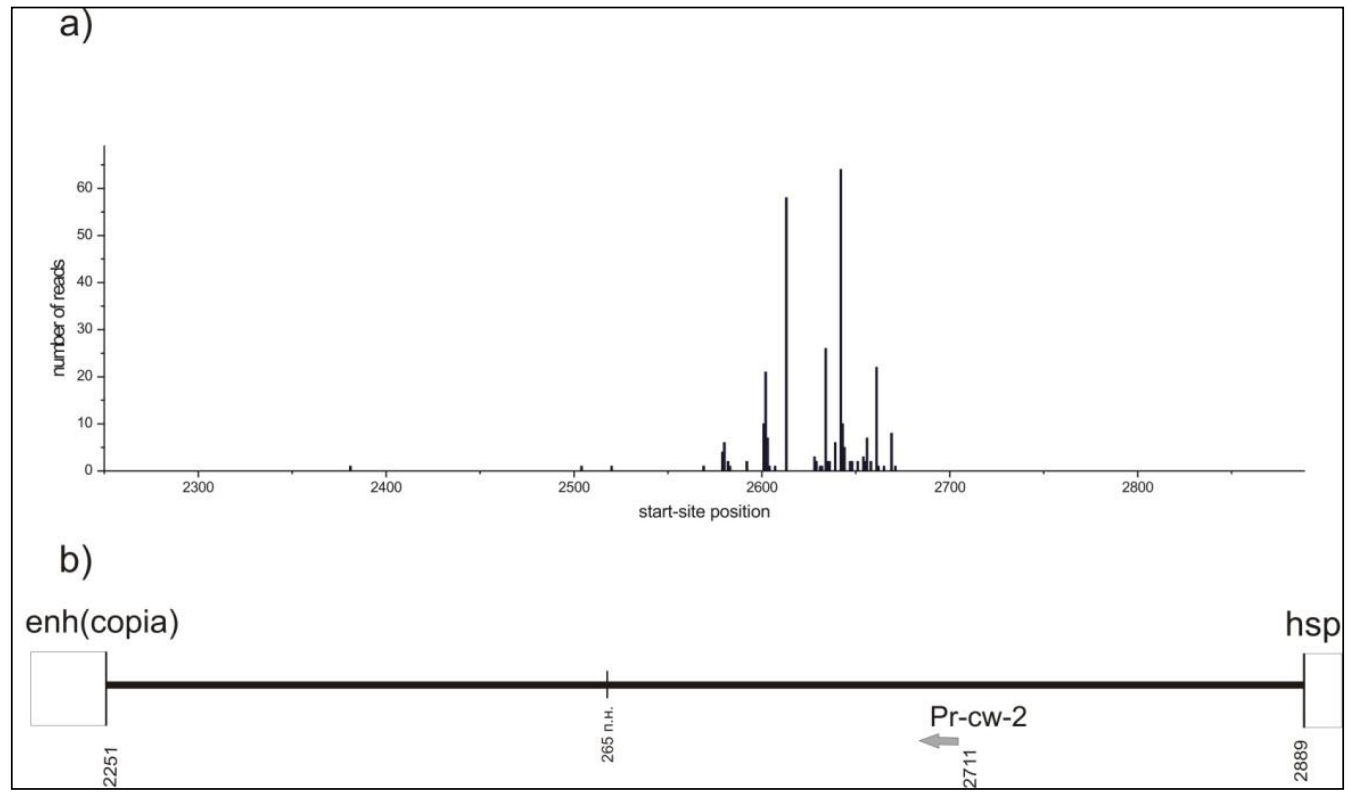

Рис. 1. Распределение стартов транскрипции на основе мультиплексного однонаправленного глубокого сиквенирования на платформе 454. a)

Распределение старт-сайтов. По оси Х указаны координаты по исходному вектору pGL3-enhancer (Promega, США). По оси Y- количество чтений. b) Схема конструкции e-h. Стрелкой указан праймер pr-cw-2, использованный для наработки PCR-продукта при 5'-RACE

Обнаружение активной транскрипции энхансерных РНК в области R3 указывает на открытую и активную конфигурацию хроматина в этой области.

Для подтверждения данной гипотезы рассмотрим модификации хроматина Н3K4me1 и Н3K27ac, которые принято ассоциировать с активными энхансерами [1], и модификации Н3K4me3 и Н3K18ac, ассоциированные с активной транскрипцией [2] в различных районах генетических конструкций. Достоинством разработанной системы является ее независимость от окружающего геномного контекста. С этой целью мы провели опыты ChIP с антителами к выбранным модифицированным гистонам.

Фрагменты ДНК после иммунопреципитации анализировались посредством количественной PCR [3] с праймерами к трем районам генетических конструкций - области энхансера (R1), области с минимальным количеством TSS эРНК (R2) и области с максимумом TSS 
эРНК (R3). Анализируя соответствующий самому энхансеру район R1, мы задействовали минус-праймер, комплиментарный последовательности вектора, что позволило следить за областью энхансера не в его геномных копиях, а лишь в самих конструкциях.

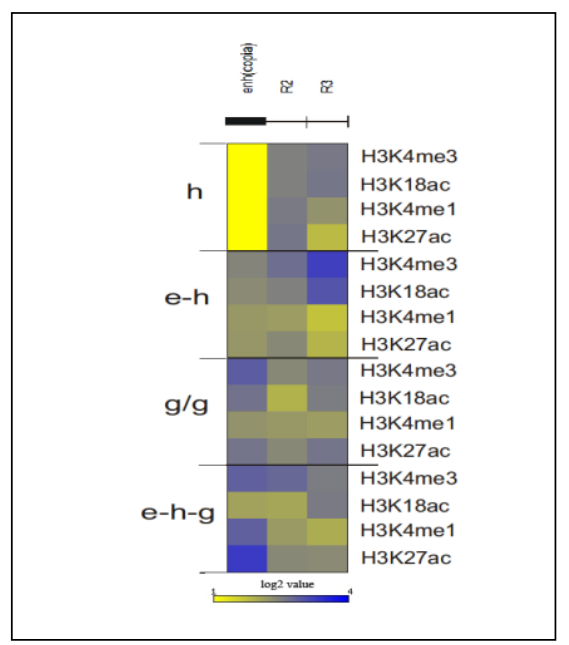

Рис. 2. Опыты по иммунопреципитации хроматина с помощью антител к модификациям гистона Н3 (Н3К4me3, Н3К4me1, Н3К18ас и НЗК27ас) в исследуемых областях конструкций. Цветная шкала показывает $\log 2$ значения интенсивности специфических модификаций гистонов в указанных районах конструкций

В ходе экспериментов был обнаружен ощутимый рост уровня H3K4me3 и Н3K18ас в конструкции e-h в направлении от энхансера к области R3, в области, где было обнаружено основное количество TSS (рис.2). Число этих меток значительно падает после введения инсулятора. Это может означать, что инсулятор gypsy действует как антагонист энхансера в данной области. К тому же, инсулятор вызывает повышение уровня Н3K27ac, Н3K4me1, and H3K4me3 на энхансере и рост уровня H3К27ас в области R3. Как правило, при проведении полногеномных исследований метка Н3К27ас связана с активными энхансерами.

Аналогичная ситуация наблюдается в модели e-h, хотя ведение инсулятора в g/g и e-h-g ведет к заметному росту ее уровня на энхансере. Возможно, эта модификация хроматина имеет отношение к энхансерам, чья деятельность подавляется активными инсуляторами. 
Не следует забывать о том, что одна из ключевых задач инсуляторов это блокирование реакции между энхансером и промотором. Впрочем, недавние опыты показали, что инсуляторы всего лишь управляют взаимодействием, а не ингибируют его [4]. Сам механизм обеспечения специфичности и стабильности этого процесса пока еще не изучен [5].

Изучение механизмов работы инсуляторов потребовало исследования связывания в разных частях используемых конструкций трех инсуляторных белков: $\mathrm{Su}(\mathrm{Hw})$ и $\bmod 2.2$, входящих в состав инсулятора gypsy, а также белка dCTCF. В ходе опытов было обнаружено, что все белки с разной интенсивностью связываются в районе энхансера в отсутствии инсулятора gypsy (конструкция e-h). Связывание $\bmod 2.2$ (рис. 3а) было особенно заметно (в том числе, в районе R2, прилежащем к энхансеру).

Впрочем, это едва ли говорит о том, что антитела к $\mathrm{Su}(\mathrm{Hw})$ или к dCTCF менее активны. Ярко выраженные сигналы при ChIP-PCR обнаруживались и при манипуляциях с этими антителами. Связывание инсуляторных белков $\mathrm{Su}(\mathrm{Hw}), \bmod 2.2$ и $\mathrm{dCTCF}$ не только с инсулятором, но и с энхансером соріа, обнаруженное нами в ходе иммунопреципитации хроматина трансфецированных генетических конструкций, тоже говорит об их участии в функционировании данного энхансера.

Связывание белков $\bmod 2.2$ и dCTCF с энхансером резко подавляется введением одной копии инсулятора в конструкцию, но сохраняется при введении пары инсуляторов (рис.3а). Таким образом, один инсулятор конкурирует с энхансером за связывание инсуляторных белков, в то время как пара инсуляторов сделать этого не может. 
a)

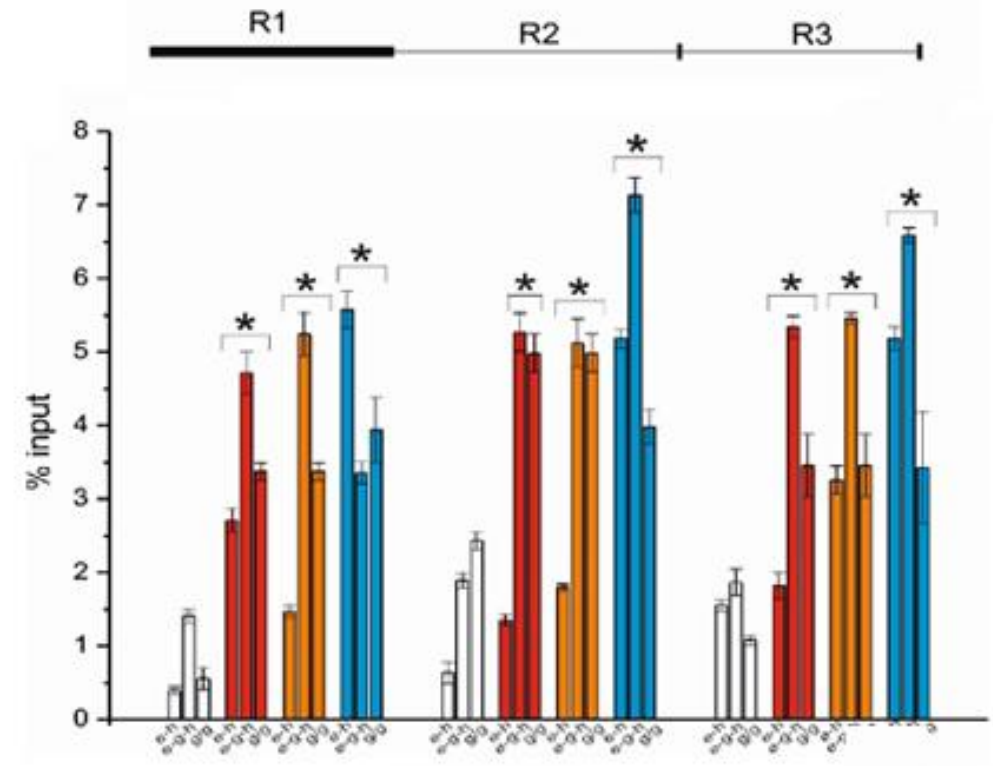

b)

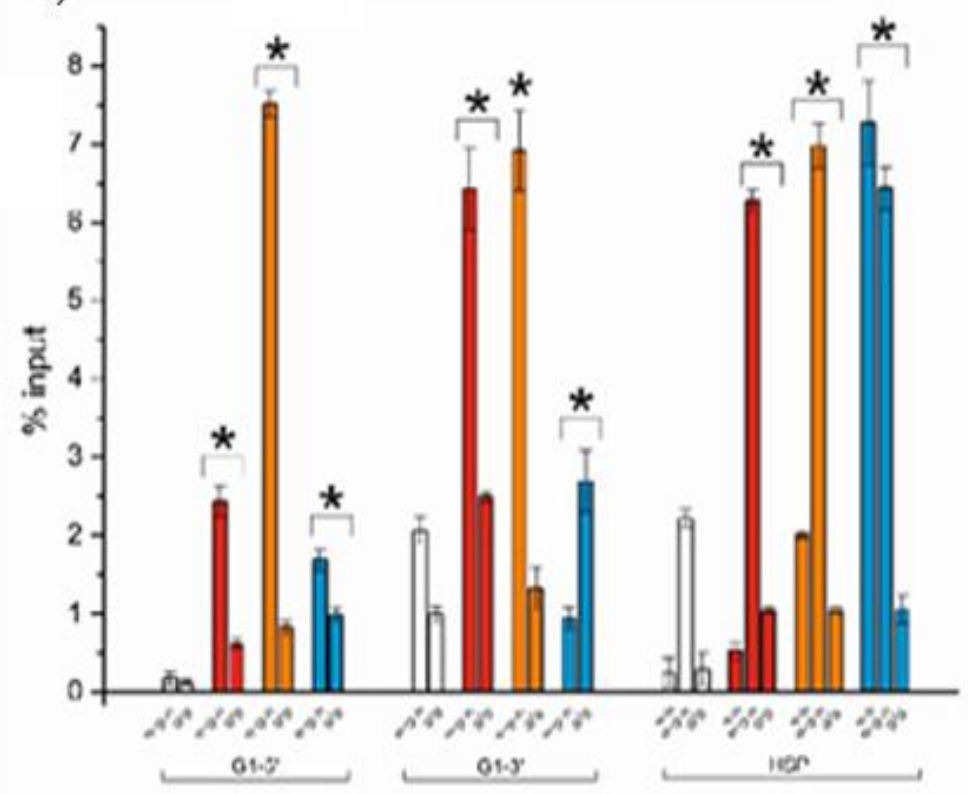

c)

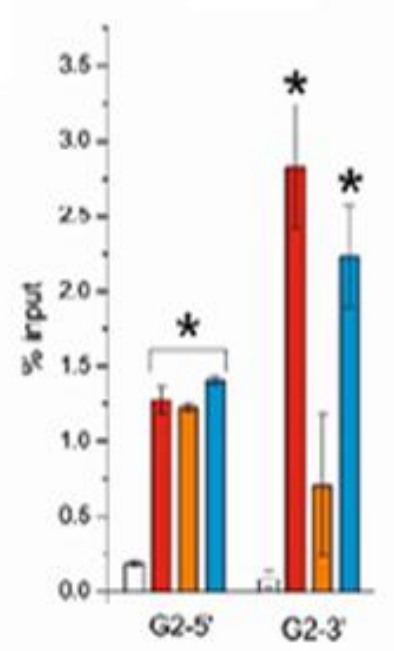

Рис. 3. Анализ связывания инсуляторных белков в различных областях конструкций e-h, e-g-h и g/g. (a) связывание инсуляторных белков с районами R1-3 (б) связывание инсуляторных белков с районами G1- 5', G1-3' и HSP (c) связывание инсуляторных белков с районами G2-5' и G2-3'

Как видно, связывание $\bmod 2.2$ обнаруживается и в районе R2, прилежащем к энхансеру. Это не говорит о том, что антитела к $\mathrm{Su}(\mathrm{Hw})$ или к dCTCF менее активны (хорошие сигналы при ChIP-PCR прослеживаются 
и в экспериментах с этими антителами). Мы видим, что инсуляторные белки $\mathrm{Su}(\mathrm{Hw}), \bmod 2.2$ и $\mathrm{dCTCF}$ связываются как с инсулятором, так и с энхансером соріа, что свидетельствует об их участии в функционировании энхансера. Это выявлено в ходе иммунопреципитации хроматина трансфецированных генетических конструкций.

Если ввести в конструкцию одну копию инсулятора, то связывание белков $\bmod 2.2$ и dCTCF с энхансером резко подавляется. Другими словами, один инсулятор успешно конкурирует за связывание инсуляторных белков с энхансером, в то время как пара инсуляторов это сделать не может.

При исследовании области первого инсулятора (районы 5'G1 и 3'G1), получена информация о связывания инсуляторных белков (рис.3а). Как и ожидалось, наблюдается связывание инсуляторных белков $\mathrm{Su}(\mathrm{Hw})$ и $\bmod 2.2$ с инсулятором gурsy.

Анализ связывания в 5' и 3' половинах второго инсулятора gypsy в конструкции g/g (5'G2 и 3'G2 на рис. 3c) показал, что белки $\mathrm{dCTCF}$ и Mod2.2 активно связываются. только в 3' половине G2. И наоборот: в первой копии инсулятора 5' половина активно связывает все белки. Эти необычные данные указывают на неравномерное распределение связывания белков dCTCF и $\operatorname{Mod} 2.2$, которое позволяет предположить, что копии инсулятора могут взаимодействовать между собой в конструкции $\mathrm{g} / \mathrm{g}$, располагаясь антипараллельно. Вдобавок существует вероятность, что районы 5'G1 и 3'G2, в которых инсуляторные белки связываются не так активно, могут образовывать контакты с другими участками хроматина, что делает их недоступными для взаимодействия. Все это соответствует литературным данным, согласно которым инсуляторы могут взаимодействовать между собой не только в составе генетических конструкций, но и в геноме $[6,7,8]$.

На основе вышесказанного мы делаем вывод о формировании комплекса, включающего энхансер и пару антипараллельно расположенных инсуляторов, которые связывают инсуляторные белки 5' половиной G1 и 3' 
половиной G2. Этому не противоречат и данные о взаимодействии инсуляторных белков с энхансером в конструкции е-h. Мы видим, что инсуляторные белки могут участвовать во взаимодействии энхансера с промотором, энхансера и инсулятора, а также между несколькими инсуляторами.

Более точный механизм этого процесса у дрозофилы требует дальнейших исследований.

Работа поддержана Программой фундаментальных исследований государственных академий наук на 2013 - 2020 годы (тема № 01201363821).

\section{Литература}

1. Heintzman N.D., Hon G.C., Hawkins R.D., Kheradpour P., Stark A., Harp L.F., Ye Z., Lee L.K., Stuart R.K., Ching C.W. et al. Histone modifications at human enhancers reflect global cell-type-specific gene expression. Nature. - 2009. - №459. - p.108-112.

2. Bernstein B.E., Kamal M., Lindblad-Toh K., et al. Genomic maps and comparative analysis of histone modifications in human and mouse. Cell. 2005. - №120 - p.169-81.

3. Tchurikov NA, Kretova OV, Fedoseeva DM, Sosin DV, Grachev SA, Serebraykova MV, Romanenko SA, Vorobieva NV, Kravatsky YV. DNA double-strand breaks coupled with PARP1 and HNRNPA2B1 binding sites flank coordinately expressed domains in human chromosomes. PLoS Genet. - 2013. - № 9(4). - e1003429.

4. Krivega I., Dean A Enhancer and promoter interactions - long distance calls. Curr Opin Genet Dev. - 2012. - №22 - P.79-85.

5. Van Bortle K., Corces V.G. The role of chromatin insulators in nuclear architecture and genome function. Curr. Opin. Genet. Dev. - 2013 - №23(2) - P. 212-218. 
6. Ong, C.T. and Corces, V.G. CTCF: an architectural protein bridging genome topology and function. Nat. Rev. Gen. - 2014. - №15. - P. 234246.

7. Phillips-Cremins.J.E. and Corces, V.G. Chromatin insulators: linking genome organization to cellular function. Mol. Cell. - 2013.- №50. - P. 461-474.

8. Comet I., Savitskaya E., Schuettengruber B., Negre N., Lavrov S., Parshikov A., Juge F., Gracheva E., Georgiev P., Cavalli G. PRE-mediated bypass of two $\mathrm{Su}(\mathrm{Hw})$ insulators targets $\mathrm{PcG}$ proteins to a downstream promoter. Dev. Cell. - 2006. - №11. - P.1-8. 